\title{
Exploring Economy Dependence in the Middle East Using Governmental Accounting Indicators: The Case of Palestine, Jordan \& Israel
}

\author{
Zahran Mohammad Ali Daraghma ${ }^{1} \&$ Raed Ali Mahmoud Iriqat ${ }^{2}$ \\ ${ }^{1}$ Accounting Department, Faculty of Administrative and Financial Sciences, Arab American University- Jenin, \\ Palestine \\ ${ }^{2}$ Business Administration Department, Faculty of Administrative and Financial Sciences, Arab American \\ University-Jenin, Palestine \\ Correspondence: Zahran Mohammad Ali Daraghma, Department of Accounting, Faculty of Administrative and \\ Financial Sciences, P. O. BOX 240, Jenin-West Bank, Palestine. Tel: 970-59-909-1041. E-mail: \\ zahran.daraghma@aauj.edu
}

Received: October 14, 2015

Accepted: November 12, 2015

Online Published: December 25, 2015

doi: 10.5539/ibr.v9n1p154

URL: http://dx.doi.org/10.5539/ibr.v9n1p154

\begin{abstract}
This paper aims at examining the causality between Palestine, Jordan, and Israel economics using three macroeconomic (governmental accounting) measurement indices: Gross Domestic Product [GDP], Inflation Rate [IR] and Unemployment Rate [UR]. In order to achieve this purpose, this manuscript employs a macroeconomic time series analysis on data gathered Palestine, Jordan, and Israel from 1997-2014. The paper employs a variety of econometric statistical methods (e.g. descriptive statistics, correlation tests, ordinary least squares, and Granger causality test). The findings of this paper statistically support the notion that both GDP in Israel and GDP in Jordan effects the Palestinian GDP. These findings put an emphasis on the dependency of the Palestinian economy on both the Jordanian and Israeli economies. Furthermore, in lieu of the findings, this study recommends that fiscal policy makers in Palestine exert serious efforts to attract additional foreign and expatriate investments, attempt to create a stable and attractive entrepreneurial and investment climate, and build national support for local products and services to minimize the interdependence. These recommendation could inspire greater confidence in the Palestinian economy and help create a better investment climate.
\end{abstract}

Keywords: governmental accounting, Paris protocol, inflation rate, unemployment, gross domestic product, Middle East

\section{Introduction}

The interconnectedness between Palestinians and Jordanians economies has been present in light of shared historical, cultural and social ties. The large number of Palestinian economic entities operating in Jordan is no hidden secret. The same cannot be said about the interdependence between the Israeli and Palestinian economies which started shortly after the creation of the state of Israel as a consequence of Israeli occupation of Palestine. However, since the creation of the Palestinian National Authority the interdependence of the Palestinian and Israeli economies has been formalized since 1993 when the Palestinian authority signed the Oslo Accord with the Israeli side. Once more in 1994 when the Palestinian and Israeli sides signed the Paris protocol. The protocol of Paris organizes the economic issues between the Palestinian Authority and Israel while the Oslo agreement arranges the political issues. As for the interdependence between the Jordanian and Israeli economies, that has gradually been formalizing since both parties signed the Wadi Araba Treaty in 1994. The previous mentioned agreements and protocols create a level of dependence among the economic variables in the three economies. Also, the manuscript of Mclister (2009) states that the association between the United States and the Canadian Gross Domestic Product [GDP] is 75\%, and the interest rate in both countries move together pretty closely. The major reason for this, of course, is the economic relation between the two countries. Also, Shmuel (2013) shows that there is a strong relationship between the interest rate in the United States and Canada. And (Mclister, 2009) states that there is a strong relationship between the inflation rates in both the Canadian and American economics. Moreover, Garfinkle (2013) shows that there is interdependence between Israel and the United States of America 
in all the dimensions of life (social, political, cultural, and economical).

Regarding the interdependence between Israel and Palestine, a high percent of the Palestinian's indirect taxes are collected by the Israeli side as stated by Oslo or Paris protocols. However, Israel resends this tax to the Palestinian Authority. Likewise, the value added tax rate in Palestine should equal the value added tax in Israel plus (minus) 0.02 according to Oslo protocol. The aforementioned facts conclude that there is a high level of economic dependence due to Oslo agreement and Paris Protocol. The next important issue is the Palestinian workforce. The Palestinian workforces rely toughly on the Israeli economy since 1948. However; the first Intifada that occurred in 1987 has been contributed in decreasing the number of Palestinian workforces to enter Israel. The Israeli government set up many barriers to prevent any entry to its areas. Nowadays the Israeli government offers permits for the Palestinian workforces under high level of restrictions (Naqib, 2015).

Regarding the used currency, Jordan uses its own currency, the Jordanian Dinar. In Israel, Israel uses its own currency, the New Shekel. In contrast, the Palestinian people use different types of currencies, for example, the Jordanian Dinar, the Israeli New Shekel and the US dollar. These indications conclude that the Palestinian economy depends on the Israeli and Jordanian currencies. However, Palestine does not issued its own currency up to now.

Countries worldwide have central banks. The central bank plays important roles in economic development such as: Issuing currency, maintaining a stable and suitable inflation rate, maintaining an interest rate structure, holding and managing the reserves in foreign currencies and gold and managing the banking system. For instance, Israel has its own central bank, bank of Israel. Jordan has the central bank of Jordan, and Palestine doesn't have its own central bank to date. However, the Palestinian National Authority established the Palestine monetary authority in 1995 to play the roles of central bank (Vecchiato, 2011).

The previous argument may show an interdependent among the three economics of Palestine, Jordan, and Israel. Unfortunately, there is a lack of concrete evidence based on the actual economic data that clearly explain which economy relies on the other. For this reason, this manuscript comes to provide a live evidence using the econometric to explain the nature of the economic relationship. This manuscript uses three economic variables. These variables are Gross Domestic Product [GDP], Inflation Rate (IR), and Unemployment Rate (UR). This paper follows an empirical methodology and based on econometric and statistical techniques to guess the dependence and causality.

This paper comprises six sections. Section (1) an introduction, section (2) addresses the literature review, section (3) describes the hypotheses of the study, section (4) addresses data and methodology, section (5) presents the results and section (6) reports the conclusion.

\section{Literature Review}

This part of the study discusses the findings of the previous literatures that investigate the economic association among countries. Regarding the economic association between the United States and Canada, the previous studies show that there is a strong relationship between the American and Canadian economies. Fergussom (2011) shows that the economies of the United States and Canada are highly integrated. He explains that the Canadian economy follows the USA economy. The USA economy dwarfs that of Canada. The USA gross domestic product (GDP) is more 9 times that of Canada in nominal terms and nearly 11 times as large in terms of purchasing power parity. In the same way, China transfers an inflation to the world where the work of (Amiti \& Choi, 2013) shows that the consumer or producer prices index in China will influence on these measures in the United States and in the world because China is the largest sole supplier of imports to the United States. In addition, the manuscript of Feyzioglu and Willard (2006) proves that the level for consumer price inflation in China leads to price changes in the United States and Japan. Similarly, (Cheung \& Yuen, 2002) find that the United States inflation has a strong impact on inflation in Hong Kong. The study of (Levine, 1995) shows that a number of the economic advantages supposed to be forthcoming with the 1993 Oslo agreement but actually most of these target benefits remain theoretically. Regarding the impact of Israel on the Palestine economy, the manuscript of (Faris, 2005) shows that the Palestinian economy relies on the Israeli economy. For instance, the Paris economic protocol states that the Israeli side is able to proceed indirect taxes which indicates that Israel will control the indirect taxes revenues (the revenue source) of the Palestinian National Authority. Also, Faris, (2005) states that the protocol of Paris obligated the Palestinian side to use Israeli shekel as the main currency. Moreover, (Wadi Araba agreement, 1994) between Jordan and Israel sides states that both countries should improve economical relationships and cooperation by increasing Intra-regional trade and ending the economic boycott of the products. Also, Wadi Araba agreement had benefits for the Palestinian enterprises. The paper of (Naqib, 2015) explores the association between the Palestinian-Israeli economics as they have established 
throughout the occupation era and the past 6 years of independence. The analysis of the relationship is within the context of two opposing impacts: a positive one that tends to expand, develop and improve the Palestinian economy then comes the negative effects that retard economic evolution and strengthen underdevelopment. Subsequently, the unemployment in Palestine will be minimized when the Israeli side allows the Palestinian workers to have an entrance to work in Israel. For instance, the manuscript of (Feiler, 1999; Farsakh, 2002) evaluates to which extent Israel relies on Palestinian workforces during the Oslo years. The authors explain that Palestinian labor flows during the Oslo years stayed significant, but they evolved in a method that reflected a process of redefinition of economic and territorial boundaries between the Israeli and the West Bank \& Gaza Strip economies. In addition, the study of (Saleh, 2007) demonstrates that the Paris economic protocol is unfair for the Palestinian Authority and negatively affects the amount of value added taxes revenues. For illustration, the Paris Protocol was signed as part of the Oslo peace agreement on the 29 April, 1994. According to this protocol, the Palestinian Authority owns the right to levy direct and indirect taxes, establish central bank (Monetary authority), obliges both parties to facilitate the continued exchange of workers, the indirect taxes on imports are collected by Israeli side and retransferred to the Palestine Authority, and imports from and exports to third countries are subject to Israeli side. The work of (Farsakh, 2002; Erekat, 2012) show that the Arab Spring affected the peace process negatively; minimize employment, and foreign investment. Regarding the Palestinian balance of trade, the paper of (Feiler, 1999) shows that Israel control over the Palestinian Authority borders, and thus over trade. For that reason, Israel control all the exports and imports of the Palestinian Authority. Thus, the Israel government has a power to control economic indicators in positively and negatively directions due to Israeli policies.

\section{The Hypotheses}

This manuscript explores the dependence (or causality) among the economies of Palestine, Jordan, and Israel. Accordingly, the following hypotheses match the previously mentioned objective. Theses hypotheses are explained as in the following:

Hypothesis 1:

There is no interdependence among (Palestinian, Jordanian, and Israeli) economics due to the Gross Domestic Product [GDP]. The first hypothesis consists of three sub-hypotheses, which are:

(H1-1): The Israeli GDP does not Granger Cause the Palestinian GDP.

(H1-2): The Israeli GDP does not Granger Cause the Jordanian GDP.

(H1-3): The Jordanian GDP does not Granger Cause the Palestinian GDP.

Hypothesis 2:

There is no interdependence among (Palestinian, Jordanian, and Israeli) economics due to the inflation rate [IR]. The second hypothesis consists of three sub-hypotheses, which are:

(H2-1): The Israeli IR does not Granger Cause the Palestinian IR.

(H2-2): The Israeli IR does not Granger Cause the Jordanian IR.

(H2-3): The Jordanian IR does not Granger Cause the Palestinian IR.

Hypothesis 3:

There is no interdependence among (Palestinian, Jordanian, and Israeli) economics due to the unemployment rate [UR]. The third hypothesis consists of three sub-hypotheses, which are:

(H3-1): The Israeli UR does not Granger Cause the Palestinian UR.

(H3-2): The Israeli UR does not Granger Cause the Jordanian UR.

(H3-3): The Jordanian UR does not Granger Cause the Palestinian UR.

\section{Methodology}

This part of the manuscript displays the data, variable measurement, and econometric models.

\subsection{Data}

This manuscript relies on three macroeconomic variables. These variables are inflation rate, unemployment rate and gross domestic product (GDP). Across sectional times series have been used for a18 years from (1997-2014). The economic data that used in this manuscript were extracted from the bulletins of the World Bank and the publications of Palestinian, Israeli, and Jordanian miniseries of economy. In this manuscript, the data were 
collected from their secondary sources as they were published by the World Bank, Palestinian government, Jordanian government, and Israeli government. The three variables of Palestine, Jordan, and Israel were measured using the American dollar.

\subsection{Variables Measurements}

Presented below are the measurements of the variables that will be used in this paper.

Firstly: Per Capita Gross Domestic Product is the Gross Domestic Product (PCGDP) divided by the number of population. This variable is measured relying on the World Bank methodology. Mathematically, the Per Capita GDP is calculated as the following (Rahman, 2013).

Using the symbol PCGDP formula:

$$
\text { PCGDP } P_{i t}=\frac{\text { Gross Domestic Product }}{\text { Number of Populations }}
$$

Where:

$$
P C G D P_{i t}=\frac{G D P_{i t}}{P N_{i t}}
$$

PCGDP $_{\mathrm{it}}$ : The per capita gross domestic product of country $\mathrm{i}$ for the period $\mathrm{t}$.

$\mathrm{GDP}_{\mathrm{it}}$ : The gross domestic product of country i for the period $\mathrm{t}$.

$\mathrm{PN}_{\mathrm{it}}$ : The number of population of country $\mathrm{i}$ for the period $\mathrm{t}$.

Secondly: Inflation rate [IR] represents an increase in the prices in a country. This study relies on the IR as disclosed by the World Bank. The World Bank measures an inflation rate using the percent of changes in the consumer price index.

Thirdly: Unemployment rate represents the percentage of labor force that is currently unemployed divided by labor forces. This variable is measured relying on the World Bank methodology. Mathematically, the Unemployment rate is calculated as the following (Rahman, 2013).

Using the symbol PCGDP formula is:

$$
U R_{i t}=\frac{\text { Number of Unemployed }}{\text { Number of Work Forces }}
$$

Where:

$$
U R_{i t}=\frac{N U_{i t}}{N W F_{i t}}
$$

$\mathrm{UR}_{\mathrm{it}}$ : The unemployment rate of country $\mathrm{i}$ for the period $\mathrm{t}$.

$\mathrm{NU}_{\mathrm{it}}$ : The number of unemployed of country $i$ for the period $t$.

$\mathrm{NWF}_{\mathrm{it}}$ : The number of work forces of country $\mathrm{i}$ for the period $\mathrm{t}$.

\subsection{Econometric Models}

This part comes to formulate the econometric models. Presented below are explanations about the hypotheses and their econometric models.

The first hypothesis comes to examine the interdependence among (Palestinian, Jordanian, and Israeli) economics due to the GDP. The first hypothesis will be examined by the Ordinary Least Squared (OLS),

\begin{tabular}{|c|c|c|}
\hline Sub-hypothesis & Model & Model \# \\
\hline $\begin{array}{c}\text { (H1-1): The Israeli GDP does not Granger Cause the } \\
\text { Palestinian GDP. }\end{array}$ & $G D P_{p t}=a_{0}+a_{1} G D P_{i t}$ & (1) \\
\hline $\begin{array}{c}\text { (H1-2): The Israeli GDP does not Granger Cause the } \\
\text { Jordanian GDP. }\end{array}$ & $G D P_{j t}=b_{0}+b_{1} G D P_{i t}$ & (2) \\
\hline $\begin{array}{l}\text { (H1-2): The Jordanian GDP does not Granger Cause } \\
\text { the Palestinian GDP. }\end{array}$ & $G D P_{p t}=c_{0}+c_{1} G D P_{j t}$ & (3) \\
\hline
\end{tabular}
correlation test, and Granger causality tests. Accordingly, the analysis should match the three sub-hypotheses of the first hypothesis. Table 1 shows each sub-hypothesis and its model.

Table 1. The OLS models for testing the first hypothesis 
Where:

$\mathrm{GDP}_{\mathrm{Pt}}$ : The gross domestic product of Palestinian economy for the period $\mathrm{t}$.

$\mathrm{GDP}_{\mathrm{Jt}}$ : The gross domestic product of Jordanian economy for the period $\mathrm{t}$.

$\mathrm{GDP}_{\mathrm{It}}$ : The gross domestic product of Israeli economy for the period $\mathrm{t}$.

$\mathrm{a}_{0}, \mathrm{~b}_{0}, \mathrm{c}_{0}$ : Constants.

$a_{1}, b_{1}, c_{1}:$ The GDP responses coefficient.

The second hypothesis comes to examine the interdependence among (Palestinian, Jordanian, and Israeli) economics due to the IR. To examine the second hypothesis, the OLS, correlation test, and Granger causality tests will be used. Accordingly, the analysis should match the three sub-hypotheses of the second hypothesis. Table 2 shows each sub-hypothesis and its model.

Table 2. The OLS models for testing the second hypothesis

\begin{tabular}{llc}
\hline \multicolumn{1}{c}{ Sub-hypothesis } & \multicolumn{1}{c}{ Model } & Model \# \\
\hline (H2-1): The Israeli IR does not Granger Cause the & $I R_{p t}=a_{0}+a_{1} I R_{i t}$ \\
Palestinian IR. & \\
(H2-2): The Israeli IR does not Granger Cause the & $I R_{j t}=b_{0}+b_{1} I R_{i t}$ \\
Jordanian IR. & \\
(H2-2): The Jordanian IR does not Granger Cause the & $I R_{p t}=c_{0}+c_{1} I R_{j t}$ \\
Palestinian IR. &
\end{tabular}

Where:

$\mathrm{IR}_{\mathrm{Pt}}$ : Inflation rate of Palestinian economy for the period $\mathrm{t}$.

$\mathrm{IR}_{\mathrm{Jt}}$ : Inflation rate of Jordanian economy for the period $\mathrm{t}$.

$\mathrm{IR}_{\mathrm{It}}$ : Inflation rate of Israeli economy for the period $t$.

$\mathrm{a}_{0}, \mathrm{~b}_{0}, \mathrm{c}_{0}$ : Constants.

$a_{1}, b_{1}, c_{1}$ : The IR responses coefficient.

The third hypothesis examines the interdependence among (Palestinian, Jordanian, and Israeli) economics due to the UR. To examine the third hypothesis, the OLS, correlation test, and Granger causality tests will be used. Hence, the analysis should match the three sub-hypotheses of the third hypothesis. Table 3 shows each sub-hypothesis and its model.

Table 3. The OLS models for testing the third hypothesis

\begin{tabular}{|c|c|c|}
\hline Sub-hypothesis & Model & Model \# \\
\hline $\begin{array}{l}\text { (H3-1): The Israeli UR does not Granger Cause the } \\
\text { Palestinian UR. }\end{array}$ & $U R_{p t}=a_{0}+a_{1} U R_{i t}$ & (7) \\
\hline $\begin{array}{l}\text { (H3-2): The Israeli UR does not Granger Cause the } \\
\text { Jordanian UR. }\end{array}$ & $U R_{j t}=b_{0}+b_{1} U R_{i t}$ & (8) \\
\hline $\begin{array}{l}\text { (H3-2): The Jordanian UR does not Granger Cause } \\
\text { the Palestinian UR. }\end{array}$ & $U R_{p t}=c_{0}+c_{1} U R_{j t}$ & (9) \\
\hline
\end{tabular}

Where:

$\mathrm{UR}_{\mathrm{Pt}}$ : Unemployment rate of Palestinian economy for the period $t$.

$\mathrm{UR}_{\mathrm{Jt}}$ : Unemployment rate of Jordanian economy for the period $t$.

$\mathrm{UR}_{\mathrm{It}}$ : Unemployment rate of Israeli economy for the period $\mathrm{t}$.

$a_{0}, b_{0}, c_{0}$ : Constants.

$\mathrm{a}_{1}, \mathrm{~b} 1, \mathrm{c} 1$ : The UR responses coefficient.

Tables 1, 2, and 3 display the OLS models that used for examining the hypotheses of this manuscript. As well, 
this manuscript uses the Pairwise Granger Causality test [GCT]. The GCT is a statistical test used for determining whether one variable is useful in explaining another. This manuscript utilizes the Granger causality test for investigating which economy will influence another. Presented below is the null hypothesis of the GCT:

The null hypothesis: $\mathrm{Y}$ does not Granger Cause $\mathrm{X}$

The null hypothesis: $\mathrm{X}$ does not Granger Cause $\mathrm{Y}$

When the $\mathrm{P}$ value $>0.05$, the null hypothesis is accepted

When the $\mathrm{p}$ value $<=0.05$, the null hypothesis is rejected

\section{The Results}

This section exhibits both the descriptive statistics, and the results of the hypotheses using appropriate econometric methods.

\subsection{Descriptive Analysis}

Table 4 displays the summary statistics of the GDP variable of Palestine, Jordan, and Israel. The time series was taken for each country from 1997-2014 (18 observations). As well, the mean of the Israeli's GDP is \$24852.99. Furthermore, the mean of the Jordanian GDP is $\$ 3049.293$. Additionally, the mean of the Palestinian GDP is $\$ 1808.29$. The previous analysis states that the average GDP per capita in Israel is the highest. In the second stage comes the Jordanian economy. In contrast, the Palestinian economy has the lowest value of the GDP per capita.

Table 4. Summary statistics of the GDP per capita in Palestine, Jordan and Israel for the period (1997-2014)

\begin{tabular}{lccccc}
\hline \multicolumn{1}{c}{ Country } & $\begin{array}{l}\text { Number of } \\
\text { Observations }\end{array}$ & Min. Value & Max. Value & Mean & $\begin{array}{l}\text { Standard } \\
\text { Deviation }\end{array}$ \\
\hline Palestine & 18 & 1156.754 & 2784.089 & 1808.295 & 586.6199 \\
Jordan & 18 & 1624.670 & 5214.197 & 3049.293 & 1348.332 \\
Israel & 18 & 18246.01 & 36163.49 & 24852.99 & 6480.365 \\
\hline
\end{tabular}

Table 5 shows the descriptive statistics of the inflation rate variable of Palestine, Jordan, and Israel. The time series was taken for each country from 1997-2014 (18 observations). Additionally, the mean of the Israeli's IR is 0.0285 ; whereas the mean of the Jordanian IR is 0.03855. In contrast, the mean of the Palestinian IR is 0.04151The previous analysis shows that the average IR in Israel is the lowest. In the second stage comes the Jordanian economy. And the Palestinian economy has the largest value of the IR.

Table 5. Summary statistics of the IR in Palestine, Jordan and Israel for the period (1997 to 2014)

\begin{tabular}{lccccc}
\hline \multicolumn{1}{c}{ Country } & $\begin{array}{c}\text { Number of } \\
\text { Observations }\end{array}$ & Min. Value & Max. Value & Mean & $\begin{array}{l}\text { Standard } \\
\text { Deviation }\end{array}$ \\
\hline Palestine & 18 & 0.01005 & 0.09890 & 0.04151 & 0.02076 \\
Jordan & 18 & -0.00678 & 0.14927 & 0.03855 & 0.03363 \\
Israel & 18 & -0.00413 & 0.09001 & 0.02850 & 0.02362 \\
\hline
\end{tabular}

Table 6 shows the descriptive statistics of the unemployment rate variable of Palestine, Jordan, and Israel. The time series was taken for each country from 1997-2014 (18 observations). Furthermore, the mean of the Israeli's UR is 0.08064 and the mean of the Jordanian UR is 0.13529. Also, the mean of the Palestinian UR is 0.22820. The previous analysis shows that the average UR in Palestine is the highest. In the middle level was the Jordanian economy. And the Israeli economy has the lowest value of the UR.

Table 6. Summary statistics of the UR in Palestine, Jordan and Israel for the period (1997-2014)

\begin{tabular}{lccccc}
\hline \multicolumn{1}{c}{ Country } & $\begin{array}{c}\text { Number of } \\
\text { Observations }\end{array}$ & Min. Value & Max. Value & Mean & $\begin{array}{l}\text { Standard } \\
\text { Deviation }\end{array}$ \\
\hline Palestine & 18 & 0.11800 & 0.30700 & 0.22820 & 0.05081 \\
Jordan & 18 & 0.12200 & 0.16200 & 0.13529 & 0.01237 \\
Israel & 18 & 0.05600 & 0.10700 & 0.08064 & 0.01541 \\
\hline
\end{tabular}




\subsection{Testing the Normality}

This section displays the results of the Jarque-Bera Normality Test. The null and alternative hypotheses of the normality are explained as the following: The null hypothesis is ( $\mathrm{X}$ variable follows the normal distribution). And the alternative hypothesis is ( $\mathrm{X}$ variable does not follows the normal distribution). Also, the decision rule is when alpha (probability) is more than 0.05.The null hypothesis should be accepted. Table 7 shows the results of the Jarque-Bera normality test for the GDP, IR, and UR of Palestinian, Jordanian, and Israeli economies. Table 7 shows that all the variables of the manuscript follow the normal distribution whereas the alpha is more than 0.05 , except Jordanian inflation rate. Accordingly, this paper can employ the parametric tests such as Pearson correlation test, simple linear regression, and the Granger causality tests.

Table 7. The results of Jarque-Bera normality test

\begin{tabular}{cccc}
\hline Country & Variable & Jarque-Bera Coefficient & Probability \\
\hline \multirow{3}{*}{ Palatine } & GDP & 2.587 & 0.274 \\
& IR & 5.304 & 0.070 \\
& UR & 1.763 & 0.413 \\
Jordan & GDP & 2.153 & 0.340 \\
& & 27.193 & 0.000 \\
& IR & 3.239 & 0.197 \\
Israel & GDP & 2.207 & 0.331 \\
& IR & 3.145 & 0.207 \\
& UR & 0.909 & 0.634 \\
\hline
\end{tabular}

\subsection{Pearson Correlation Test}

Table 8 shows the outcomes of Pearson correlation test for the time series of the Palestinian, Jordanian, and Israeli Gross Domestic Product (GDP). The correlation test demonstrates the following findings. Firstly, there is a significant positive relationship between the Palestinian GDP and the Jordanian GDP of the pooled data; whereas the correlation coefficient is 0.952 and statistically is significant at 0.01 . This indicates that there is a strong dependence between the two economies (Palestine and Jordan). Secondly, there is a significant positive relationship between the Palestinian GDP and the Israeli GDP of the pooled data; whereas the correlation coefficient is 0.969 and statistically is significant at 0.01 . This indicates that there is a strong dependence between the two economies (Palestine and Israel). Thirdly, there is a significant positive relationship between the Jordanian GDP and the Israeli GDP of the pooled data whereas the correlation coefficient is 0.982 and statistically is significant at 0.01 . This indicates that there is a strong dependence between the two economies (Jordan and Israel).

Table 8. Summary statistics of Pearson correlation test for the GDP of Palestine, Jordan, and Israel

\begin{tabular}{cccc}
\hline Variable Name & GDP $_{\text {Palestine-t }}$ & GDP $_{\text {Jordan-t }}$ & GDP $_{\text {Israel-t }}$ \\
\hline GDP $_{\text {Palestine-t }}$ & 1 & $0.952^{* * * *}$ & $0.969^{* * *}$ \\
& & 0.000 & 0.000 \\
GDP $_{\text {Jordan-t }}$ & & 1 & $0.982^{* * *}$ \\
& & & 0.000 \\
\hline
\end{tabular}

Table 9 illustrates the results of Pearson correlation test for the time series of the Palestinian, Jordanian, and Israeli Inflation Rate (IR). The correlation test demonstrates the following findings. Firstly, there is a significant positive relationship between the Palestinian IR and the Jordanian IR of the pooled data; whereas the correlation coefficient is 0.525 and statistically is significant at 0.05 . This indicates that there is a strong dependence between the two economies (Palestine and Jordan). Secondly, there is a significant positive relationship between the Palestinian IR and the Israeli IR of the pooled data whereas the correlation coefficient is 0.671 and statistically is significant at 0.01 . This indicates that there is a strong dependence between the two economies (Palestine and Israel). Thirdly, there is an insignificant positive relationship between the Jordanian IR and the Israeli IR of the pooled data; whereas the correlation coefficient is 0.032 and statistically is insignificant. This indicates that there is independence between the two economies (Jordan and Israel). 
Table 9. Summary statistics of Pearson correlation test for the IR of Palestine, Jordan, and Israel

\begin{tabular}{cccc}
\hline Variable Name & $\mathrm{IR}_{\text {Palestine-t }}$ & $\mathrm{IR}_{\text {Jordan-t }}$ & $\mathrm{IR}_{\text {Israel-t }}$ \\
\hline IR $_{\text {Palestine-t }}$ & \multirow{2}{*}{} & $0.525^{* * *}$ & $0.671^{* * *}$ \\
& & 0.025 & 0.002 \\
$\mathbf{I R}_{\text {Jordan-t }}$ & & 1 & 0.032 \\
& & & 0.901 \\
\hline
\end{tabular}

Table 10 displays the results of Pearson correlation test for the time series of the Palestinian, Jordanian, and Israeli Unemployment Rate (UR). The correlation test demonstrates the following findings. Firstly, there is an insignificant positive relationship between the Palestinian UR and the Jordanian UR of the pooled data whereas the correlation coefficient is 0.360 and statistically is insignificant. This indicates that there is independence between the two economies (Palestine and Jordan). Secondly, there is an insignificant positive relationship between the Palestinian UR and the Israeli UR of the pooled data; whereas the correlation coefficient is 0.187 and statistically is insignificant. This indicates that there is independence between the two economies (Palestine and Israel). Thirdly, there is a significant positive relationship between the Jordanian UR and the Israeli UR of the pooled data whereas the correlation coefficient is 0.677 and statistically is significant at 0.01 . This indicates that there is a strong dependence between the two economies (Jordan and Israel).

Table 10. Summary statistics of Pearson correlation test for the UR of Palestine, Jordan, and Israel

\begin{tabular}{cccc}
\hline Variable Name & UR $_{\text {Palestine-t }}$ & $\mathrm{UR}_{\text {Jordan-t }}$ & $\mathrm{UR}_{\text {Israel-t }}$ \\
\hline UR $_{\text {Palestine-t }}$ & 1 & 0.360 & 0.187 \\
& & 0.142 & 0.458 \\
UR $_{\text {Jordan-t }}$ & & 1 & $0.677^{* * *}$ \\
& & & 0.002 \\
\hline
\end{tabular}

\subsection{Testing the Hypothesis}

Table 11 shows the statistics of the ordinary least squared (OLS) which inspect the first hypothesis of this paper. The first hypothesis comes to test the interdependence among (Palestinian, Jordanian, and Israeli) economics due to the Gross Domestic Product [GDP].The statistics of the pooled time series of the GDP point out the following findings: (1) There is a significant positive impact of Israeli GDP on the Palestinian GDP; whereas the coefficient is 0.087 and statistically is significant at 0.01 . The value of the R squared is 0.939 and the F-value is 244.85. (2) There is a significant positive impact of Israeli GDP on the Jordanian GDP; whereas the coefficient is 0.204 and statistically is significant at 0.01 . Therefore, the value of the R squared is 0.965 and the F-value is 440.98. (3) There is a significant positive impact of Jordanian GDP on the Palestinian GDP whereas the coefficient is 0.414 and statistically is significant at 0.01 . The value of the R squared is 0.906 and the F-value is 153.82 .

Table 11. The OLS summary statistics of the first hypothesis (the interdependence between economies according to the GDP) $\left(G D P_{i t}=a_{0}+\mathrm{a}_{1} G D P_{i t}\right)$

\begin{tabular}{cccccc}
\hline $\begin{array}{c}\text { Causal } \\
\text { Relationship }\end{array}$ & Constant & Coefficient & F-Value & $\begin{array}{c}\mathrm{R} \\
\text { Square }\end{array}$ & $\begin{array}{c}\text { Adj. R } \\
\text { square }\end{array}$ \\
\hline Palestine - Israel & $-371.4 * *$ & $0.087^{* * *}$ & $244.85^{* * * *}$ & 0.939 & 0.935 \\
& $(-2.58)$ & $(15.65)$ & & & \\
Jordan - Israel & $-2030^{* * *}$ & $0.204^{* * *}$ & $440.98^{* * *}$ & 0.965 & 0.963 \\
& $(-8.14)$ & $(21.00)$ & & & \\
Palestine - Jordan & $545.7 * * *$ & $0.414^{* * *}$ & \multirow{2}{*}{$153.82^{* * *}$} & 0.906 & 0.900 \\
\hline
\end{tabular}

Table 12 shows the statistics of the ordinary least squared (OLS) which inspect the second hypothesis of this paper. The second hypothesis comes to test the interdependence among (Palestinian, Jordanian, and Israeli) economics due to the Inflation Rate [IR]. The statistics of the pooled time series of the IR point out the following findings: (1) There is a significant positive impact of Israeli IR on the Palestinian IR; whereas the coefficient is 
0.590 and statistically is significant at 0.01 . The value of the R squared is 0.450 and the F-value is 13.11 . (2) There is a significant positive impact of Israeli IR on the Jordanian IR whereas the coefficient is 0.045 and statistically is significant at 0.05 . Therefore, the value of the R squared is 0.21 and the F-value is 3.71. (3) There is a significant positive impact of Jordanian IR on the Palestinian IR whereas the coefficient is 0.324 and statistically is significant at 0.01 . The value of the R squared is 0.276 and the F-value is 6.09 .

Table 12. The OLS summary statistics of the second hypothesis (the interdependence between economies according to the IR) $\left(I R_{i t}=a_{0}+a_{1} I R_{i t}\right)$

\begin{tabular}{|c|c|c|c|c|c|}
\hline $\begin{array}{c}\text { Causal } \\
\text { Relationship }\end{array}$ & Constant & Coefficient & F-Value & $\begin{array}{c}\mathrm{R} \\
\text { Square }\end{array}$ & $\begin{array}{l}\text { Adj. R } \\
\text { square }\end{array}$ \\
\hline Palestine - Israel & $\begin{array}{c}0.0247 * * * * \\
(4.14)\end{array}$ & $\begin{array}{c}0.590 * * * \\
(3.62)\end{array}$ & $13.11 * * *$ & 0.450 & 0.416 \\
\hline Jordan - Israel & $\begin{array}{c}0.0373 * * * \\
(2.86)\end{array}$ & $\begin{array}{c}0.045^{* *} \\
(2.81)\end{array}$ & $3.71 * *$ & 0.210 & 0.000 \\
\hline Palestine - Jordan & $\begin{array}{c}0.029 * * * \\
(4.37)\end{array}$ & $\begin{array}{c}0.324 * * \\
(2.47)\end{array}$ & $6.09 * * *$ & 0.276 & 0.230 \\
\hline
\end{tabular}

Table 13 shows the statistics of the ordinary least squared (OLS) which inspect the third hypothesis of this paper. The third hypothesis comes to test the interdependence among (Palestinian, Jordanian, and Israeli) economics due to the Unemployment Rate [UR]. The statistics of the pooled time series of the UR point out the following findings: (1) There is an insignificant positive impact of the Israeli UR on the Palestinian UR; whereas the coefficient is 0.616 and statistically is insignificant. The value of the R squared is 0.035 and the F-value is 0.58 . (2) There is a significant positive impact of Israeli UR on the Jordanian UR whereas the coefficient is 0.543 and statistically is significant at 0.01 . Therefore, the value of the $\mathrm{R}$ squared is 0.458 and the F-value is 13.53 . (3) There is an insignificant positive impact of Jordanian UR on the Palestinian UR whereas the coefficient is 1.48 and statistically is insignificant. The value of the R squared is 0.13 and the F-value is 2.39 .

Table 13. The OLS summary statistics of the third hypothesis (the interdependence between economies according to the UR) $\left(U R_{i t}=a_{0}+a_{1} U R_{i t}\right)$

\begin{tabular}{cccccc}
\hline $\begin{array}{c}\text { Causal } \\
\text { Relationship }\end{array}$ & Constant & Coefficient & F-Value & $\begin{array}{c}\mathrm{R} \\
\text { Square }\end{array}$ & $\begin{array}{c}\text { Adj. R } \\
\text { square }\end{array}$ \\
\hline Palestine - Israel & $0.179^{* *}$ & 0.616 & 0.58 & 0.035 & 0.000 \\
& $(2.69)$ & $(0.76)$ & & & \\
Jordan - Israel & $0.092^{* * *}$ & $0.543^{* * *}$ & $13.53 * * *$ & 0.458 & 0.424 \\
Palestine - Jordan & $(7.55)$ & $(3.68)$ & & & \\
& 0.028 & 1.48 & 2.39 & 0.13 & 0.076 \\
\hline
\end{tabular}

\subsection{Additional Evidence (Granger Causality Test)}

Table 14 shows the statistics of pairwise Granger causality tests. The test states that the Israeli GDP does Cause the Palestinian GDP. Also, The Jordanian GDP does Cause the Palestinian GDP. These findings show that the Palestinian economy relies on the Jordanian and Israeli economics. These findings are consistent with the ordinary least squared results. 
Table 14. Results of pairwise Granger causality tests

\begin{tabular}{ccc}
\hline The Null Hypothesis & F-Statistic & Alpha \\
\hline The Israeli GDP does not Granger Cause the Palestinian GDP. & 4.114 & 0.0463 \\
The Israeli GDP does not Granger Cause the Jordanian GDP. & 2.086 & 0.1705 \\
The Jordanian GDP does not Granger Cause the Palestinian GDP. & 11.619 & 0.0019 \\
The Israeli IR does not Granger Cause the Palestinian IR. & 0.079 & 0.9239 \\
The Israeli IR does not Granger Cause the Jordanian IR. & 2.996 & 0.0914 \\
The Jordanian IR does not Granger Cause the Palestinian IR. & 0.66917 & 0.53180 \\
The Israeli UR does not Granger Cause the Palestinian UR. & 0.40769 & 0.67483 \\
The Israeli UR does not Granger Cause the Jordanian UR. & 2.09087 & 0.16998 \\
The Jordanian UR does not Granger Cause the Palestinian UR. & 0.13387 & 0.87610 \\
\hline
\end{tabular}

Note. * If the value of the alpha is more than 0.05 , the null hypothesis must be accepted.

\section{Conclusion}

This paper aims to examine the causality between Palestine, Jordan, and Israel economics using three measures of macroeconomics variables. The three variables are Gross Domestic Product [GDP], Inflation Rate [IR] and Unemployment Rate [UR]. To achieve the previous mentioned objective, this paper employs the time series data of the macroeconomics variables in the three countries from 1997-2014.Also, this paper utilizes the following econometric methods (descriptive statistics, correlation tests, ordinary least squares, and Granger causality test). The findings of this paper state that the Palestinian economy relies on the Jordanian and Israeli economies. Thus, this paper recommends the decision makers in Palestine to attract additional investments, creating suitable investment climate, and encouraging the local product to minimize the interdependence.

\section{References}

Amiti, M., \& Choi, M. (2013). China's Impact on U.S. Inflation. Liberty Street Economics. January 14.

Bernhardsen, T. (2000). The Relationship between Interest Rate Differentials and Macroeconomic Variables: A Panel Data Study for European Countries. Journal of International Money and Finance, 19(2), 289-308. http://dx.doi.org/10.2469/dig.v31.n1.806

Cheung, Y. W., \& Jude, Y. (2002). Effects of U.S. Inflation on Hong Kong and Singapore. Journal of Comparative Economics, 30, 603-619. http://dx.doi.org/10.1006/jcec.2002.1787

Clive, G. (1969). Investigating Causal Relations by Econometric Models and Cross-spectral Methods. Econometrica, 37(3), 424-438. http://dx.doi.org/10.2307/1912791. JSTOR 1912791

Erekat, S. (2012). Changes in the Arab World and Their Repercussions on the United States of America and the West, Palestine and Israel. The Palestine-Israel Journal, 18(2\&3).

Faris, N. (2005). Valuation of the Palestinian-Israeli Tariff Relationships and the Capabilities for Achieving Economic Independence. Ministry of National Economy. Ramallah-Palestine.

Farsakh, L. (2002). Palestinian Labor Flows to the Israeli Economy: A Finished Story? Journal of Palestine Studies, 32(1), 13-27. http://dx.doi.org/10.1016/j.jdeveco.2012.08.007

Feiler, G. (1999). Investments in the Palestinian and Jordanian Economies. The Palestine-Israel Journal, 6(3).

Fergusson, I. (2011). United States-Canada Trade and Economic Relationship: Prospects and Challenges. Congressional Research Service. Prepared for Members and Committees of Congress. www.crs.gov.

Feyzioğlu, T., \& Willard, L. (2006). Does Inflation in China Affect the United States and Japan? International Monetary Fund: IMF. Asia and Pacific Department. IMF Working Paper. http://dx.doi.org/10.5089/9781451862966.001

Garfinkle, A. (2013). The Triangle Connecting the U.S., Israel, and American Jewry May Be Coming Apart. Tablet Magazine. November 5. Retrieved from http://tabletmag.com.

Levine, M. (1995). Palestinian Economic Progress under the Oslo Agreements. Fordham International Law Journal, 19(4), 1391-1418.

Mclister, R. (2009). America's Impact on Canadian Interest Rates. Mortgage Commentary. November 9th. Retrieved from http://www.canadianmortgagetrends.com

Naqib, F. (2015). Economic relations between Palestine and Israel during the occupation era and the period of 
limited self-rule. Economic Research Forum for the Arab Countries Ira. Working Paper series.

Paris P. (1994). Gaza-Jericho Agreement, Annex IV-Economic Protocol: Protocol on Economic Relations between the Government of the State of Israel and the P. L. O., representing the Palestinian people. Retrieved from http://mfa.gov.il

Rahman, S. (2013). Relationship among GDP, Per Capita GDP, Literacy Rate and Unemployment Rate. British Journal of Arts and Social Sciences, 14(2), 169-177.

Saleh, M. (2007). Factors Affecting the Value Added Taxes (VAT) Revenues of the Palestine National Authority: Empirical Study. Unpublished Master thesis, Islamic University-Gaza, Gaza-Palestine.

Serena, V. (2011). Palestine Monetary Authority: Striving for stable banks. International Capital Market Association. Retrieved from www.icmagroup.org.

Shmuel, J. (2013). Will the U.S. Fed raise interest rates before the Bank of Canada? Financial Post. Retrieved from http://business.financialpost.com.

Wadi Araba agreement. (1994). Treaty of Peace between the State of Israel and the Hashemite Kingdom of Jordan. Wadi Araba- Jordan. October 26, 1994.

\section{Copyrights}

Copyright for this article is retained by the author(s), with first publication rights granted to the journal.

This is an open-access article distributed under the terms and conditions of the Creative Commons Attribution license (http://creativecommons.org/licenses/by/3.0/). 